\title{
XXXIX. A letter to the editors relating to the ellipticity of the earth as deduced from experiments with the pendulum
}

\author{
J. Ivory M.A. F.R.S.
}

To cite this article: J. Ivory M.A. F.R.S. (1828) XXXIX. A letter to the editors relating to the ellipticity of the earth as deduced from experiments with the pendulum , Philosophical Magazine Series 2, 3:16, 241-243, DOI: 10.1080/14786442808674636

To link to this article: http://dx.doi.org/10.1080/14786442808674636

曲 Published online: 10 Jul 2009.

Submit your article to this journal $₫$

Џll Article views: 2

Q View related articles $\longleftarrow$

Citing articles: 1 View citing articles $\square$ 
'THE

\title{
PHILOSOPHICAL MAGAZINE
}

\author{
A ND \\ ANNALS OF PHILOSOPHY. \\ [NEW SERIES.] \\ $A P R I L 1828$.
}

XXXIX. A Letter to the Editors relating to the Ellipticity of the Earth as deduced from Experiments with the Pendulum. By J. Ivory, M.A. F.R.S.

Gentlemen,

IN examining the calculations in the articles relative to the ellipticity of the earth, inserted in the last Number of this Journal, I have detected a small arithmetical error, which, although of little moment, it may be proper to correct. The equation at the bottom of p. 170 , viz.

$$
\begin{array}{cc} 
& 2 \cdot 973 \tau=-\cdot 00061, \\
\text { should be, } & 2 \cdot 973 \tau=-\cdot 00033: \\
\text { consequently, } \tau=-.00011, \quad s=+00005, \\
f=\cdot 2056, \quad \Delta=\cdot 01335 ;
\end{array}
$$

and the formula for the length of the pendulum,

$$
l=39 \cdot 01335+\cdot 2056 \sin ^{2} \lambda \text {. }
$$

But the error just corrected is so small as not to affect either the reasoning deduced from the formula at the top of $\mathrm{p} .171$, or any of the results obtained by it.

It is directed in p. 207, that the two approximate quantities $a$ and $b$, be so taken as to satisfy equation (A): but it is obvious that, although this be convenient, it is not necessary in the method of computation I have followed. Nothing more is required than that $a$ and $b$ nearly satisfy equation (A); in which case the right-hand side of equation (B), will not be equal to zero, but to a small known quantity positive or negative, - a circumstance which makes no essential difference in finding the corrections $s$ and $\pi$.

From the calculations which have been made, we may infer Nere Series. Vol. 3. No. 16. April 1828. 2 I that 
that no great confidence can be placed in the ellipticity deduced from any partial combination of the experiments with the pendulum: for we have found that there is considerable uncertainty in the value of that element, even when we avail ourselves of all the experiments we at present possess. This matter will be placed in a clear light by setting before the reader, the values of $\Delta$, or of the excess of the pendulum at the equator above 39 inches, which we have obtained by taking different means of the tropical experiments, viz.

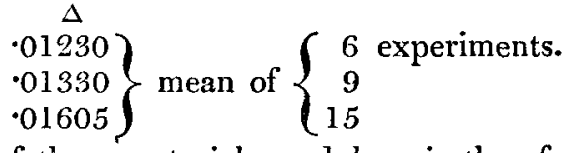

The true value of the equatorial pendulum is therefore very uncertain. If we take the first mean of six tropical experiments, and neglect the other nine, we shall obtain, by combining the 31 remaining experiments, a formula for the length of the pendulum coinciding very nearly with that published in this Journal for October 1826, the ellipticity being about $5 \frac{1}{0} \sigma^{\text {. }}$ The other two means are the bases of the calculations in the two papers inserted in the last Number of this Journal. A strict scrutiny of the experiments would perhaps bear us out in adopting $3_{3}^{\frac{1}{0}} \overline{0}$ as the ellipticity that best agreed with the bulk of them; but any ellipticity between $3^{\frac{1}{0} 0}$ and $\frac{1}{2} \frac{1}{6}$ will represent sufficiently well 34 out of the 40 experiments in our possession. The ellipticity $\frac{1}{2} \frac{1}{89}$ does not represent with much accuracy, either the six anomalous experiments, or the remaining 34 ; and in the present state of our knowledge, we may consider it a thing nearly demonstrated, that this value is too great.

What is most remarkable in the experiments with the pendulum, is their excessive irregularity near the equator. This is well illustrated by the four values of $\Delta$ following, which are experimental quantities, not the results of calculation, viz.

\begin{tabular}{|c|c|c|}
\hline & $\begin{array}{l}\text { Longitude. } \\
44^{\circ} 21^{\prime} \text { W. }\end{array}$ & .01173 \\
\hline & 131 I E. & .01479 \\
\hline : & $90 \quad 0 \quad \mathrm{~W}$. & $\cdot 01717$ \\
\hline 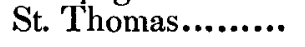 & $645 \mathrm{E}$ & $\cdot 02074$ \\
\hline
\end{tabular}

The longitudes are set down, as all the stations are so near the equator, that they may be reckoned upon it. If the same irregularity shall be found to prevail upon all the parallels, it must be acknowledged that the figure of the earth, deduced from such incoherent data, will lose much of the interest and utility, which are usually attached to it. But no such irregu- 
Earth as deduced from Experiments with the Pendulum. 24.8

larity has hitherto been experienced beyond the tropics; and even between the tropics there are only a few stations at which so great an excess of gravity has been observed as excludes them from belonging to the same surface as the other experiments. I apprehend it cannot be said at present that the great anomalies alluded to, are so well ascertained as to render any further inquiry unnecessary in regard to their exact quantity, or to the causes which produce them: and the determination of these points in preference to any other, seems to claim the attention of the experimenter; because it must fix in a great degree the complexion of the whole theory. Can we hope to determine an elliptical surface that will represent all the experiments within the limits of the probable errors of observation? Or, must we be content with a mean elliptical figure liable to great discrepancies? These seem at present to be the most interesting questions in this research. The least attention to the position of the anomalous stations on the surface of the globe, will prove how fruitless it would be, to suppose that the experiments can be better represented by a figure different from the elliptical spheroid. Far less can we expect, in the present state of our knowledge, to attain any useful purpose by pushing the theoretical solution of the figure of the earth to quantities of the second order; because the corrections thus introduced must be ultimately determined by the experiments themselves, the uncertainties of which greatly surpass the quantities to be found.

I remain, Gentlemen,

Your obedient servant,

March 12, 1828.

J. Ivory.

XL. Remarks on the Geology of the North Side of the Vale of Pickering. By John Phillips, F.G.S., Keeper of the Museum of the Yorkshire Philosophical Society.*

[With an Engraving.]

THE principal object of this communication is to explain some of the peculiar appearances which are exhibited along the southern edge of the oolitic hills which margin the Vale of Pickering from Seamer to Helmsley.

My attention was first drawn to a part of this country by a visit to Kirkdale Cave, in company with Mr. Salmond and Mr. Smith, in March 1824. In August of the same year I had further opportunity of examining with the aid of a barometer, the whole line during my walk from York to Scarborough.

* Read to the Yorkshire Philosophical Society, Jan. 1, 1828; and communicated by the Author. 